\title{
Structural optimisation and experimental analysis of composite material panels for naval use
}

\author{
G. Marannano, G. Virzì Mariotti
}

Dipartimento di Meccanica, Università di Palermo - Viale delle Scienze, 90128 Palermo, Italy.

\begin{abstract}
The purpose of the work is the realization of a composite material with long glass fibers having better characteristic than a fiber random composite, to permit the reduction of weight and costs to shipyards for pleasure craft. Structural optimization is performed by ANSYS for the choice of the layers disposition to obtain the maximum stiffness with minimum material employment, saving weight. The study is centered on the research of the better configurations of plies packing in relation of pure shear stress for four different plies. Unidirectional plies, both symmetric orthotropic and symmetric nonorthotropic ones, are realized successively by the vacuum bag technique. Experimental tests of traction, bending, inter laminar shear and pure shear are executed to characterize the three different type of material. Experimental results are compared to ones obtained numerically to validate the procedures; the comparison with the analytical results permitted to attribute an adequate value to shape factor of the fibers. In all the cases the optimization permitted the construction of much more resistant plies than random ones, with a lower thickness.
\end{abstract}

Key words: random composite, composite material test, structural optimization.

\section{INTRODUCTION}

This work takes rise on a previous work [1] for the characterization of a random composite in use in the naval industry. The shipyard for pleasure craft achieves the parts in composite material in order to obtain the best compromise of strength, stiffness, weight and cost of the structures with the purpose to achieve performances that cannot be obtained by traditional materials. In general the shipyards do not put great attention in the building of fiber glass laminated, that is they do not consider the possibility of obtaining more strength laminates to several solicitations characteristics, simply disposing the strength fibers in an adequate direction. The study of the typology of the plies and their correct arrangement is finalized to the obtaining of the maximum strength with the minimum employment of material, assuring a greater mobility and a lower energy request for the boat motion. The purpose of the paper is the realization of a composite material with long fibers having better general characteristics than a random composite material having normal use in the naval industry. The developed work is summarized in the following points:

- Initial material: composite with random glass fibers supplied by a boat manufacturer [1]. In this paper the existing rules for materials with unidirectional fibers are applied in all cases to specimens dimension and to the procedure of test execution [2], [3], [4], [5]. The experimental tests are conduced on a Hounsfield test machine, equipped with a load cell of $20 \mathrm{kN}$. The plies are realized with 8 layers in composite material, to reach the thickness in the rule range $(2-3 \mathrm{~mm})$.

- Characterization of the random laminate

- Optimization by ANSYS, to choose the ply disposition to obtain the maximum stiffness with the minimum material employment. In particular the study is centered on the research of the best 
configuration of the ply packing for four different laminates shown in the table 3 besides the program is instructed to choose layers of the same thickness in order to avoid problems of construction.

- Realization of unidirectional, Symmetric Orthotropic (SO) and Symmetric Non Orthotropic (SNO) plies by the technique of the vacuum bag. Fiber orientation obtained by numerical optimization is adopted for each configuration.

- Experimental tests of traction, bending, pure shear and inter-laminar shear to characterize the three types of material, following the above rules and using the above test machine.

- Comparison of the experimental results with those obtained by numerical and analytical analysis to validate the procedure.

\section{PRELIMINARY ANALYSIS}

It consists in the characterization of random panels; table 1 shows the more significant data obtained by a series of tests on random plies.

Table 1. Characteristics of the composite material with random fibres

\begin{tabular}{|c|c|c|c|c|c|}
\hline \multicolumn{2}{|c|}{ Elastic Modulus } & \multicolumn{2}{|c|}{ Poisson Ratio } & \multicolumn{2}{c|}{ Shear Modulus } \\
\hline $\mathbf{E}_{\mathrm{x}}$ & $\mathbf{9 4 9 3} \mathrm{MPa}$ & $\mathbf{V}_{\mathrm{xy}}$ & $\mathbf{0 . 4 3}$ & $\mathbf{G}_{\mathrm{xy}}$ & $3322 \mathrm{MPa}$ \\
\hline $\mathbf{E}_{\mathrm{y}}$ & $\mathbf{9 4 9 3} \mathrm{MPa}$ & $\mathbf{V}_{\mathrm{yz}}$ & $\mathbf{0 . 4 3}$ & $\mathbf{G}_{\mathrm{yz}}$ & $3322 \mathrm{MPa}$ \\
\hline $\mathbf{E}_{\mathrm{z}}$ & $2010 \mathrm{MPa}$ & $\mathbf{V}_{\mathrm{xz}}$ & $\mathbf{0 . 3 3}$ & $\mathbf{G}_{\mathrm{xz}}$ & $\mathbf{1 1 0 7} \mathrm{MPa}$ \\
\hline
\end{tabular}

The comparison with the correspondent results on composites FRP permits the evaluation of the advantages obtained using the structural optimization, exploiting the strongly directional mechanical properties: in fact varying the fiber orientation one can obtain plies having the desired overall behavior.

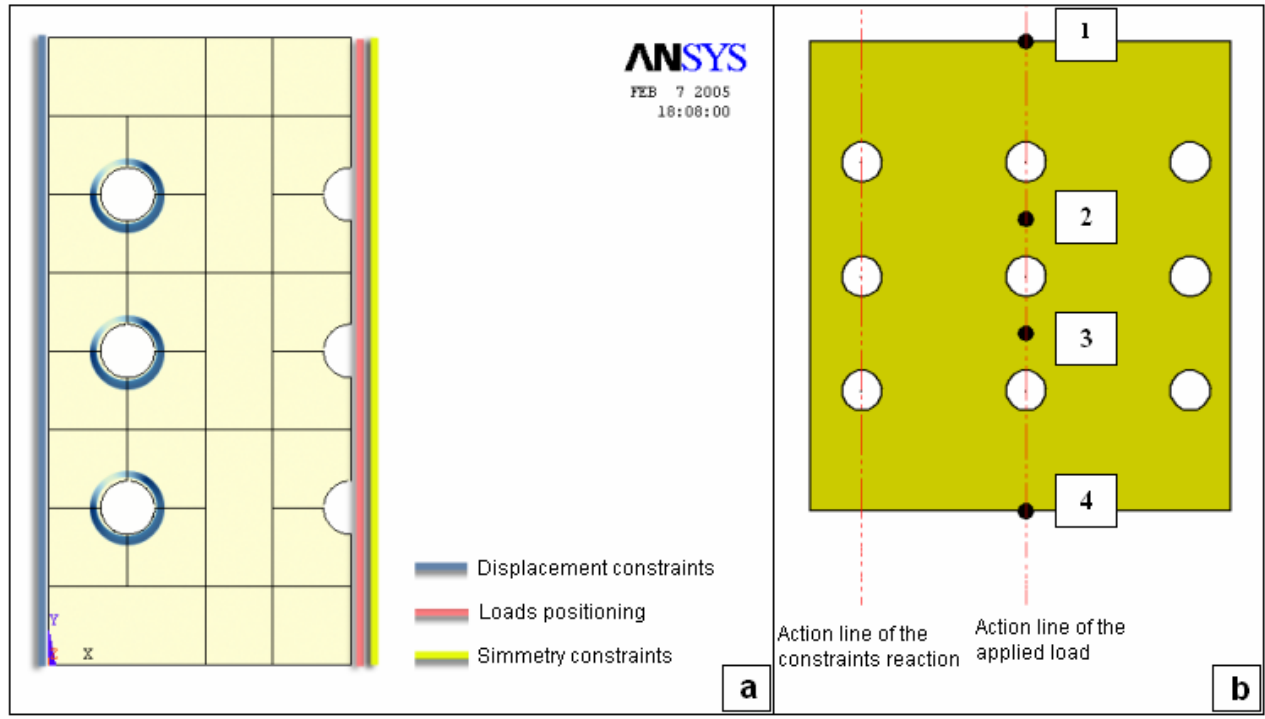

Fig. 1 - Positioning of loads and constraints

\section{STRUCTURAL OPTIMIZATION}

The structural optimization [6] is an analytical-numerical procedure that gives the best configuration of a component performing specific functions required by the designer. The purpose of the optimization is the determination of the direction of the fibers in plies with unidirectional long fibers of glass and polyester resin constituted by 8 layers and subjected to pure shear, in order to reduce the thickness compared to plies constituted by random fibers having equal stiffness.

The optimization was executed by Numerical FEM analysis by ANSYS. In the first approximation the model of the random specimen was reproduced [1] and the shear test was executed by the method "Three Rail Shear Test" [5]. A plane model was realized, meshing by "solid" elements named 
"Plane42" with four nodes. Mechanical and physical material properties are defined with the plies thickness, having linear elastic orthotropic behavior; the elastic characteristics shown in table 1 are used as input.

Table 2. Variables and objective of the optimization

\begin{tabular}{|l|l|}
\hline Design Variables & $\begin{array}{l}\text { The fibers orientation }\left(\text { variable } 0^{\circ}-180^{\circ} \text { ) and the thickness of a single plate in the }\right. \\
\text { interval } 0,15-0,5 \mathrm{~mm}\end{array}$ \\
\hline State Variables & $\begin{array}{l}\text { The displacements achieved by the four points of the specimen realized in random } \\
\text { composite (fig. 1). These values cannot be excessive. }\end{array}$ \\
\hline Objective function & $\begin{array}{l}\text { The thickness of the plates obtained by the optimization analysis. The state variable } \\
\text { determines an admissible dominion of the thickness variation in order to obtain a reliable } \\
\text { configuration. }\end{array}$ \\
\hline
\end{tabular}
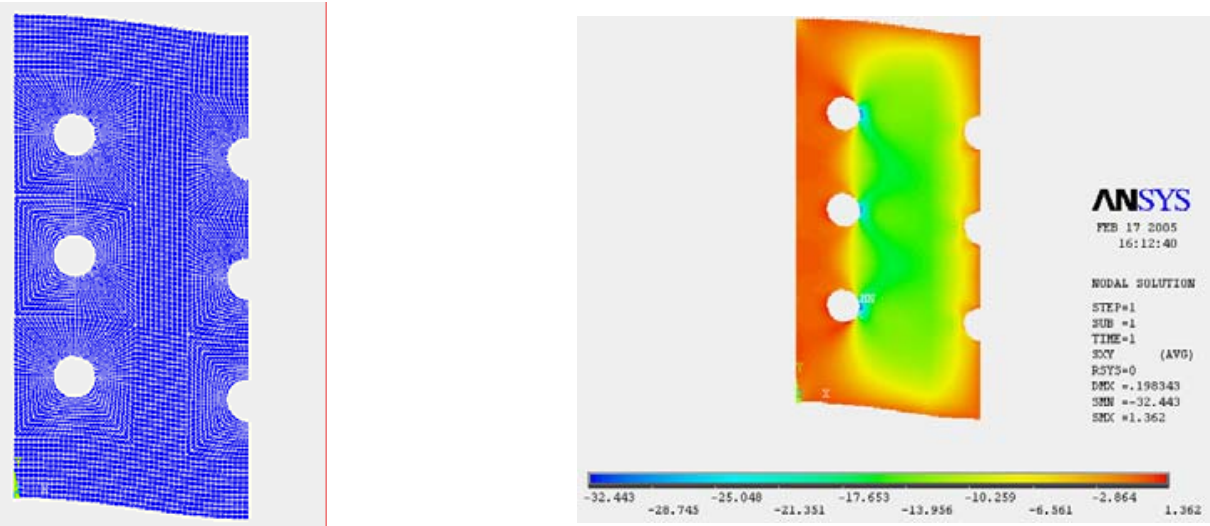

Fig. 2 - a) deformation of the specimen loaded in pure shear b) Stress field $\tau_{x y}$

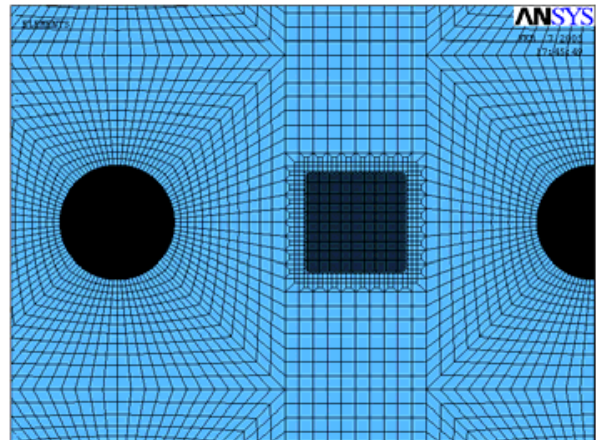

Fig. 3 - Mesh of the specimen near to the central holes

A half structure only is meshed due to the geometrical symmetry of load and constraint (fig. 1a). The specimen is constrained in correspondence of the holes in the left and right side by bolts; the holes on the central part are useful to apply the loads. The numerical analysis allows to obtain the strain in the zones indicated by the dark points in figure $1 \mathrm{~b}$. The displacements of the points $1,2,3,4$ constitute the state variables for the stiffness optimization of the directional composite. Table 2 shows the variables and the objective function for the numerical optimization of the long fibers composite.

The figures $2 \mathrm{a}$ and $\mathrm{b}$ show respectively the deformed specimen and the stress $\tau_{\mathrm{xy}}$; the stress has a little variation in a large central zone, subjected to quasi-pure shear.

\subsection{Analysis and numerical calculation}

Modeling of composite materials requires the choice of the more suitable element, the definition of the configuration, of the plies orientation, etc. The numerical problem is approached fixing some main points:

1. Initialization of the analysis, introducing the necessary optimization variables.

For the four different ply types in Table. 3, one has defined: Simm $=1$ (yes) or 2 (no).

$\mathrm{H}_{\mathrm{i}}=$ thickness of i-th plies 
$\mathrm{T}_{\mathrm{i}}=$ orientation of the $\mathrm{i}$-th plies

Table 3. - The four types of plies in study and optimisation variables

\begin{tabular}{||c|c||}
\hline \hline Non Symmetric - Non Orthotropic & Symmetric - Non Orthotropic \\
\hline Simm $=2$ & Simm $=1$ \\
$\mathrm{H}_{\mathrm{i}}=\mathrm{H}_{\mathrm{j}}$ if $\mathrm{i} \neq \mathrm{j}$ & $\mathrm{H}_{\mathrm{i}}=\mathrm{H}_{\mathrm{j}}$ if $\mathrm{i} \neq \mathrm{j}$ \\
$\mathrm{T}_{\mathrm{i}} \neq \mathrm{T}_{\mathrm{j}}$ if $\mathrm{i} \neq \mathrm{j}$ & $\mathrm{T}_{\mathrm{i}} \neq \mathrm{T}_{\mathrm{j}}$ if $\mathrm{i} \neq \mathrm{j}$ \\
\hline Non Symmetric - Orthotropic & Symmetric - Orthotropic \\
\hline Simm $=2$ & Simm $=1$ \\
$\mathrm{H}_{\mathrm{i}}=\mathrm{H}_{\mathrm{j}}$ if $\mathrm{i} \neq \mathrm{j}$ & $\mathrm{H}_{\mathrm{i}}=\mathrm{H}_{\mathrm{j}}$ if $\mathrm{i} \neq \mathrm{j}$ \\
$\mathrm{T}_{\mathrm{i}+1}=-\mathrm{T}_{\mathrm{i}}$ if impair & $\mathrm{T}_{\mathrm{i}+1}=-\mathrm{T}_{\mathrm{i}}$ if $\mathrm{i}$ impair \\
\hline
\end{tabular}

2. Individuation of the elements type to employ.

A plane model is realized meshing with layer elements named "shell 91" [6], having eight nodes and six degrees of freedom for each node; it can be employed to mesh both classical composite structures constituted by more layers, and sandwich structures. Thickness and orientation of fibers are specified in parametric way for each layer.

According to the classical theory of the lamination, the element does not admit sliding among the layers; a generic segment that is initially rectilinear and orthogonal to the mean plane has to stay rectilinear and orthogonal to the mean plane after the deformation. Stress varies linearly along the thickness of each layer.

3. Mesh of the structure in an adequate number of elements

Fig. 3 shows the mesh near to the central holes of the specimen. Note the finer mesh in correspondence of the zone subjected to quasi-pure shear.

4. Application of loads and constraints, as in fig. 1 .

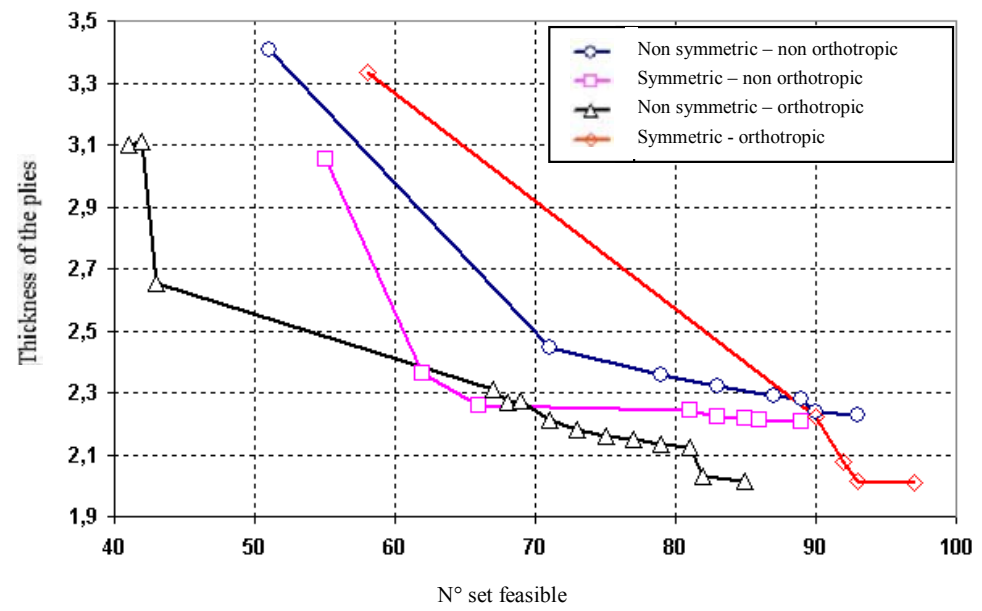

Fig. 4. Convergence of the objective function for the four types of plies

5. Instruction to the solutor regarding the model

A single loop analysis is preliminarily planned in the ANSYS optimization module in order to determine the first feasible set; successively an optimization random cycle constituted by 50 iterations is run. Data obtained from each step permitted the instruction of the solutor in the best way during the successive iterations in sub-problem: 500 iterations have been performed for every type of plies.

\subsection{Optimisation results}

The analysis requires much calculation time; figure 4 shows the convergence of the objective function. Table 4 gives the optimum value of the thickness and the corresponding orientation of the plies after completion of the numerical analysis. Besides it gives the thickness percentage reduction obtained by 
numerical optimization. One can note the considerable thickness reduction obtained employing plies with long unidirectional fibers.

Table 4 - Optimisation results of every single layer for the plies in study

\begin{tabular}{|c|c|c|c|}
\hline Type of plies & Thickness [mm] & $\begin{array}{c}\text { Thickness reduction \% } \\
\text { compared to fiber } \\
\text { random composites }\end{array}$ & Plies Orientation [degrees] \\
\hline Random & 5.30 & $\#$ & $\#$ \\
\hline $\begin{array}{c}\text { Non symmetric } \\
\text { Non orthotropic }\end{array}$ & 2,2283 & $\approx 57 \%$ & {$[178 / 120 / 95 / 75 / 80 / 85 / 178 / 105]$} \\
\hline $\begin{array}{c}\text { Symmetric } \\
\text { Non orthotropic }\end{array}$ & 2,2071 & $\approx 58 \%$ & {$[102 / 72 / 74 / 100]$ symmetric } \\
\hline $\begin{array}{c}\text { Non symmetric } \\
\text { Orthotropic }\end{array}$ & 2,0136 & $\approx 62 \%$ & {$[94 /-94 / 94 /-94 / 86 /-86 / 77 /-77]$} \\
\hline $\begin{array}{c}\text { Symmetric } \\
\text { Orthotropic }\end{array}$ & 2.0099 & $\approx 62 \%$ & {$[80 / 100 / 95 / 85]$ symmetric } \\
\hline
\end{tabular}

Table 5 - Characteristics of the plies

\begin{tabular}{|c|c|c|c|}
\hline Plies dimensions & $\mathrm{mm}$ & 210 & 300 \\
$\mathrm{~N}^{\circ}$ layers & & & 8 \\
Total surface & $\mathrm{m}^{2}$ & & 0.504 \\
Weight & $\mathrm{gr}$ & & 154 \\
Basis weight & $\mathrm{gr} / \mathrm{m}^{2}$ & $(295)$ & 305.5556 \\
\hline Plies weight & $\mathrm{gr}$ & & 225 \\
weight f \% & & & 68.44444 \\
\hline Resin density & $\mathrm{gr} / \mathrm{cm}^{3}$ & & 1.4 \\
Hardening density & $\mathrm{gr} / \mathrm{cm}^{3}$ & & 0.95 \\
Total density & $\mathrm{gr} / \mathrm{cm}^{3}$ & & 1.386893 \\
\hline Fiber density & $\mathrm{gr} / \mathrm{cm}^{3}$ & & 2.54 \\
Plies density & $\mathrm{gr} / \mathrm{cm}^{3}$ & & 2.0121 \\
Volume f \% & & & $\mathbf{5 4 . 2 1 9 3 1}$ \\
\hline
\end{tabular}

Table 6 - Characteristics of the constructed specimens

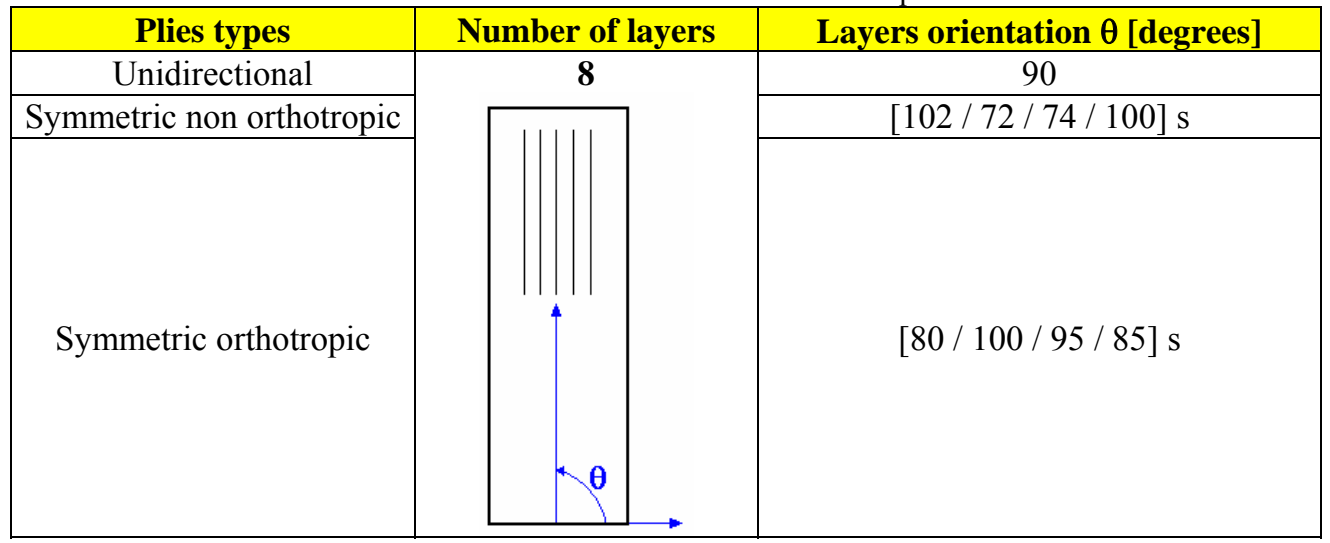

\section{PLIES ACHIEVEMENT}

To perform the experimental test, to compare and evaluate the analytical and numerical results the decision is made to build symmetric and unidirectional specimens only, because the application of the curing to non-symmetric plies would cause their bending out of plane. Table 5 shows the realized plies characteristics to execute experimental tests. The value of $54 \%$ is reached thanks to the use of vacuum bag technique and cannot be obtained by the normal lay-up at room temperature. The constructive characteristics of the specimens are shown in table 6. 


\subsection{Vacuum bag preparation}

The sealant is spread on the perimeter of the plate; a thin foil of anti-adhesive is placed between the aluminium mould and the composite material. Then a foil of micro-holed and the fabric for the air ventilation; another film is placed over the last, to separate the plies from the aluminium plate (thickness $10 \mathrm{~mm}$ ). It is useful to compress uniformly the composite when it is subjected to vacuum. At the end the thin film of the vacuum bag is spread on the sealing strip on the mould perimeter, in order to create a closed volume for the pressure reduction. A pump generates an under pressure of 0,85 $\div 0,9$ bar inside the vacuum bag. The system is positioned inside an oven to receive a curing cycle controlled in the following way:

- Gradual heating of $3-5^{\circ} \mathrm{C} /{ }^{\prime} 1$ to $80^{\circ} \mathrm{C}$.

- Maintenance of this temperature for 60 minutes.

- Gradual cooling of $3-5^{\circ} \mathrm{C} /{ }^{\prime} 1$ to room temperature. A fast cooling can produce internal residual stress and cracks.

The plies are then machined for the specimens preparation.

\section{ANALYTICAL CALCULATIONS}

Plies characteristic depends on the volumetric ratio fiber-matrix, one indicates by $V_{f}$ e $V_{m}$ the volumetric ratio fiber-composite and matrix-composite defined by:

$V_{f}=\frac{v_{f}}{v_{c}} \quad V_{m}=\frac{v_{m}}{v_{c}}$

being $v_{f}, v_{m}$ e $v_{c}$ the volumes of fibers, matrix and composite respectively.

The productive process "vacuum bag", used to realize the plies, permits to reach a percentage in volume of fibers equal to $54 \%$, it determines the characteristic of composite materials. Table 7 shows the characteristics of employed fibers and matrix.

Table 7 - Characteristics of fiber and matrix used to plies production

\begin{tabular}{|c|c|c|c|c|}
\hline Mechanical Characteristics & \multicolumn{2}{|c|}{ Fibre } & \multicolumn{2}{c|}{ Matrix } \\
\hline Longitudinal elastic modulus & $\mathrm{E}_{\mathrm{lf}}$ & $70000 \mathrm{MPa}$ & $\mathrm{E}_{\mathrm{lm}}$ & $2010 \mathrm{MPa}$ \\
\hline Transversal elastic modulus & $\mathrm{E}_{\mathrm{tf}}$ & $70000 \mathrm{MPa}$ & $\mathrm{E}_{\mathrm{tm}}$ & $2010 \mathrm{MPa}$ \\
\hline Longitudinal Poisson ratio & $\mathrm{v}_{\mathrm{lff}}$ & 0.22 & $v_{\mathrm{ltm}}$ & 0.38 \\
\hline Transversal Poisson ratio & $\mathrm{v}_{\mathrm{tf}}$ & 0.22 & $\mathrm{v}_{\mathrm{tlm}}$ & 0.38 \\
\hline Longitudinal shear modulus & $\mathrm{G}_{\mathrm{ltf}}$ & $2869 \mathrm{MPa}$ & $\mathrm{G}_{\mathrm{ltm}}$ & $760 \mathrm{MPa}$ \\
\hline
\end{tabular}

Assuming linear elastic behavior, longitudinal elastic modulus $\mathrm{E}_{1}-\mathrm{E}_{\mathrm{L}}$ can be calculated by [7]:

$E_{l}=E_{f} \cdot V_{f}+E_{m} \cdot V_{m}$

that is the expression of the mixture rule. Transversal elastic modulus $\mathrm{E}_{2}-\mathrm{E}_{\mathrm{T}}$ is:

$E_{c}=E_{f} /\left(V_{f}+\frac{E_{f}}{E_{m}} \cdot V_{m}\right)$

that is a non-linear relation. The mixture rule does not give exact values. A more complex theoretical method can be used, as the Halpin-Tsai one [7]:

$\eta=\left(\frac{E_{f}}{E_{m}}-1\right) /\left(\frac{E_{f}}{E_{m}}+\xi\right) \quad E_{T}=\frac{1+\xi \eta \cdot V_{f}}{1-\eta \cdot V_{f}} \cdot E_{m}$ 
where $\xi$ is a shape factor. Shear Elastic modulus $\mathrm{G}_{12}-\mathrm{G}_{\mathrm{LT}}$ is [7]:

$$
\left(1+\frac{V_{m}}{V_{f}}\right) \cdot \frac{1}{G_{T L}}=\frac{1}{G_{f}}+\frac{V_{m}}{V_{f}} \cdot \frac{1}{G_{m}}
$$

This relation does not give exact values either; a better assessment of the transversal elastic modulus is obtained using the following relation:

$$
\eta=\left(\frac{G_{f}}{G_{m}}-1\right) /\left(\frac{G_{f}}{G_{m}}+\xi\right) \quad G_{L T}=\frac{1+\xi \eta \cdot V_{f}}{1-\eta \cdot V_{f}} \cdot G_{m}
$$

Poisson ratio $v_{12}-v_{\mathrm{LT}}$ is [7]:

$v_{L T}=v_{f} \cdot V_{f}+v_{m} \cdot V_{m}$

Poisson ratio $v_{\mathrm{TL}}$ is determined by the Young modules $\mathrm{E}_{\mathrm{L}}, \mathrm{E}_{\mathrm{L}}$, and Poisson ratio $v_{\mathrm{LT}}$ by [7]:

$v_{T L}=\frac{E_{T}}{E_{L}} v_{L T}$

A direct comparison of the results obtained by the classical lamination theory with the experimental result shows an error on the shear modulus of about $25 \%$. The explanation is that the simplified model of Halpin Tsai theory depends on the fiber cross section by $\xi$ factor.This assumes the value 2 for fibers with circular section, and the value $\xi=2 a / b$ for rectangular section; where "a" is the dimension of the fiber side parallel to applied load, and " $b$ " is the dimension of the other. The comparative analysis shows that a value $\xi=3$ can be attributed to the plies in study; in this way the analytical shear modulus differs from the experimental one by $2 \%$ only.

\section{Experimental tests and results}

Experimental tests of traction, bending, interlaminar shear and pure shear are executed on the constructed plies. The materials show a different behavior under the imposed load conditions.
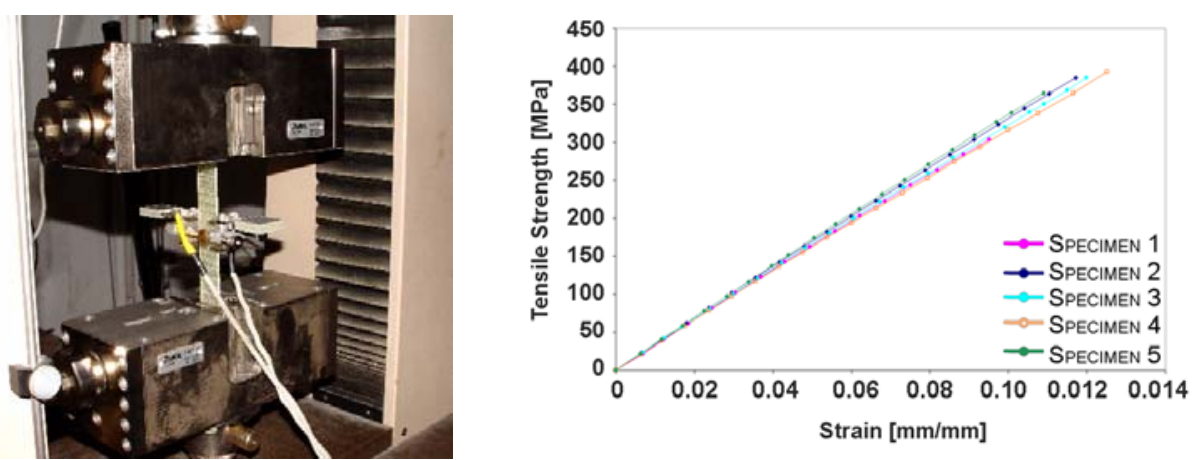

Fig. 5 Tensile test on Housfield and results on the symmetric- non orthotropic material

\subsection{Tensile test [2]}

Fig. 5 shows the Hounsfield test machine and the specimen and an example of experimental result. The strain gauge is connected to an UPM 100 unit for the data acquisition. Some specimens broke in a zone out of the central one, so that the results were discarded. 

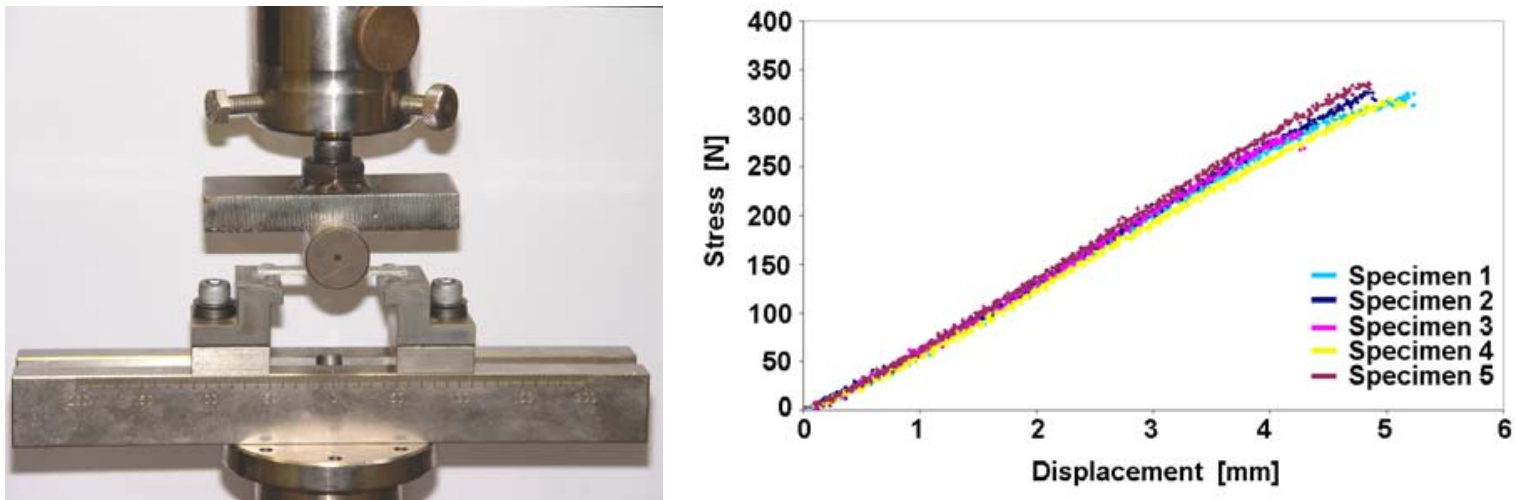

Fig. 6 - Bending test and results on the symmetric non orthotropic material
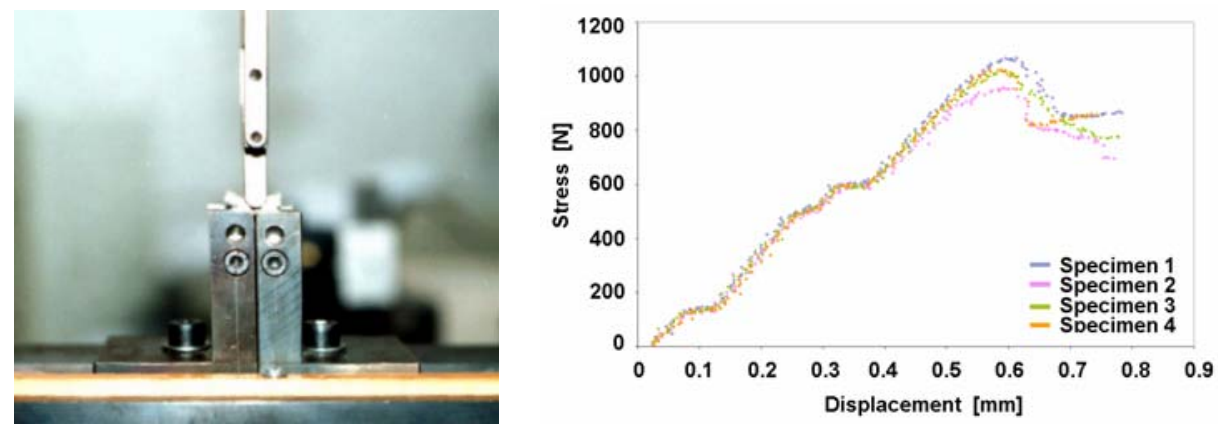

Fig 7 - Interlaminar shear test and displacement-load curve for the unidirectional composite

\subsection{Bending test [3]}

Three point bending test is executed loading the middle of the specimen until the fibers break. Fig. 6 shows the load system and an example of result. The load cell is connected to a computer by a National Instruments card; the data are processed by adequate software. The plot is interrupted when the breakage of the first layer occurs; ultimate strength and elastic modulus are calculated in the usual way.

\subsection{Interlaminar shear test [4]}

This test permits the determination of the ply behavior when it is subjected to actions producing large delaminating. It is a bending test on short specimens with rectangular section. Fig. 7 shows the test procedure and the load-displacement curves acquired in the way described in the previous paragraph 5.2 .

\subsection{Shear test [5]}

American standard ASTM D4255 considers plies with unidirectional fibers as random composite. The test is conducted using a set "Three Rail Shear Test" (fig. 8). This load system consists of a support carrying two lateral uprights, to constraint the specimen, and by a punch sliding $10 \mathrm{~mm}$ on the vertical. The specimen is fastened to the lateral uprights by six bolts $\varnothing 10$, tightened by a dynamometric wrench with a torque of $85 \mathrm{Nm}$; three other bolts connect the specimen to the punch. The load is applied in compression on the punch with a velocity $1 \mathrm{~mm} /{ }^{\prime} 1$, insuring a quasi-pure shear stress in the central zone of the specimen, as FEM analysis results show in fig. 2b. Two strain gauge rosettes 6/350RY83 are installed in this zone to measure the deformations (fig. 9). Grids A1 and B3 take care of the deformation measurement along the direction at $+45^{\circ}$, while the grids $\mathrm{A} 3$ e $\mathrm{B} 1$ measure those along the direction $-45^{\circ}$, and $\mathrm{A} 2$ and $\mathrm{B} 2$ along the direction $0^{\circ}$. An UPM 100 unit records both load and deformation values; the obtained results are shown in fig. 10 for the unidirectional specimen. 

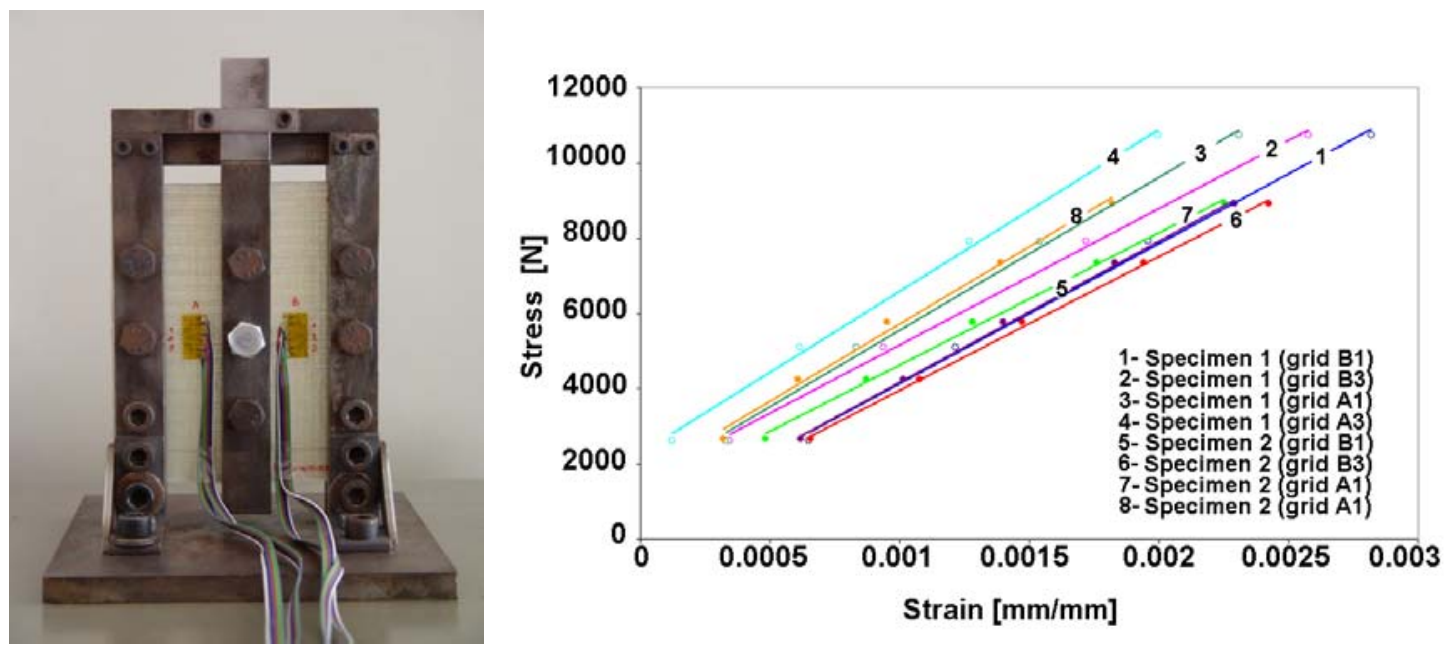

Fig. 8 - "Three Rail Shear Test" and results of the shear test on unidirectional specimen
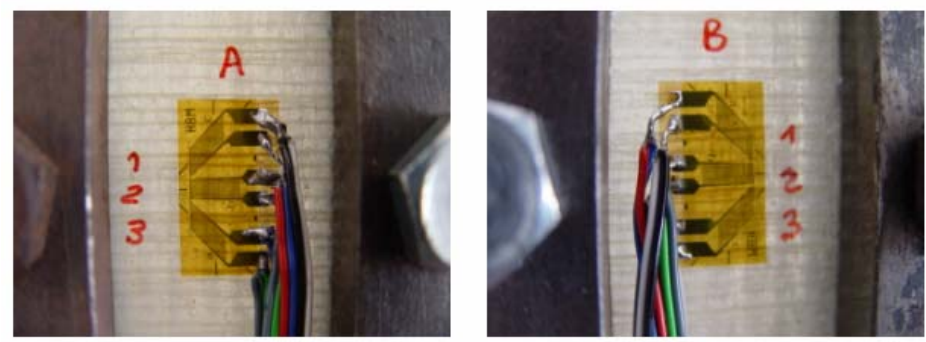

Fig. 9 - Particular of the strain gauges installed on the specimen surface on two different sides of the specimen

\section{5 Results}

Table 8 shows the mean values of the obtained results for all the plies; the comparison is executed with the random material, having a percentage in fibers equal to $30 \%$ of the volume and the percentage improvement of the plies compared to the random composite.

Table 8 - Summary of the experimental results and percentage improvement of the strength characteristics compared to fiber random composite ones.

\begin{tabular}{|c|c|c|c|c|c|c|c|c|}
\hline & & Unidir. & Unidir.\% & SO & SO \% & SNO & SNO \% & Random \\
\hline \multirow{4}{*}{ Traction } & $\overline{\mathrm{E}[\mathrm{MPa}]}$ & 38047,67 & $\approx 348$ & 34574,7 & $\approx 307$ & 32319,6 & $\approx 280$ & 8486,4 \\
\hline & $\sigma_{\mathrm{r}}[\mathrm{MPa}]$ & $>370,60$ & $>360$ & $>371,05$ & $>360$ & $>366,32$ & $>355$ & 80,62 \\
\hline & $\varepsilon_{\mathrm{r}}$ & $>0,0099$ & $>4$ & $>0,011$ & $>16$ & $>0,011$ & $>16$ & 0,0095 \\
\hline & $\mathrm{E}$ [MPa] & 37763,17 & $\approx 300$ & 33235,7 & $\approx 250$ & 31021,2 & $\approx 228$ & 9459,46 \\
\hline \multirow[t]{2}{*}{ Bending } & $\sigma_{r}[\mathrm{MPa}]$ & 978,07 & $\approx 528$ & 696,12 & $\approx 347$ & 665,16 & $\approx 327$ & 155,7 \\
\hline & $\varepsilon_{r}$ & $\sim 0,026$ & $\approx 62$ & $\sim 0,021$ & $\approx 31$ & $\sim 0,021$ & $\approx 31$ & $\sim 0,016$ \\
\hline \multirow[t]{2}{*}{ Interlaminar shear } & $\tau_{\mathrm{r}}[\mathrm{MPa}]$ & 43,84 & $\approx+74$ & 40,9 & $\approx+62$ & 38,86 & $\approx+54$ & 25,2 \\
\hline & $\mathrm{G}_{12}[\mathrm{MPa}]$ & 3676,43 & $\approx 26$ & 3913,07 & $\approx 35$ & 7479,85 & $\approx 157$ & 2909,45 \\
\hline \multirow[t]{2}{*}{ Pure shear } & $\tau_{\mathrm{r}}[\mathrm{MPa}]$ & 34,46 & $>103$ & 33,59 & $>124$ & 37,66 & $>151$ & $\sim 15$ \\
\hline & $\gamma_{\mathrm{r}}$ & 0,0115 & $>538$ & 0,015 & $>733$ & 0,0091 & $>105$ & 0,0018 \\
\hline
\end{tabular}

Shear modulus $\mathrm{G}_{12}$ for both the plies $\mathrm{SO}$ and $\mathrm{SNO}$ is evaluated by numerical analysis. The model is reproduced taking advantage of the geometry and load symmetry, with a finer mesh in the zone of strain gauges application (fig. 3). Imposing a load history equal to experimental one, strain values $\varepsilon_{\mathrm{x}}$, $\varepsilon_{\mathrm{y}} \mathrm{e} \gamma_{\mathrm{xy}}$ are calculated in the application points of the rosettes. The following relation evaluates the grid deformation at $+45^{\circ}$ :

$\varepsilon_{45^{\circ}}=\left(\varepsilon_{x}+\varepsilon_{y}+\gamma_{x y}\right) / 2$ 
Now the load - strain curve can be plotted, and the value of the numerical analysis can be interpolated by a straight line for the materials in study. The shear modulus is obtained by the following relationship:

$G_{12}=P_{l} /(4 \cdot s \cdot h)$

where: $P_{l}$ is the slope of the linear part of the load-strain curve, $\mathrm{s}$ is the specimen thickness in $\mathrm{mm}$ and $\mathrm{h}$ the specimen height in $\mathrm{mm}$. Table 9 shows the results obtained by the numerical analysis and the percentage variations compared to experimental results. In conclusion the FEM model can be believed valid because the strain values are comparable to the experimental ones, with a very low error.

Table 9 - Comparison between numerical and experimental results in pure shear test

\begin{tabular}{|c|c|c|c|}
\hline Plies & Numerical result $\mathrm{G}_{12}[\mathrm{MPa}]$ & Experimental result $\mathrm{G}_{12}[\mathrm{MPa}]$ & Variation [\%] \\
\hline SO & $\mathbf{4 1 0 2 , 5 1}$ & $\mathbf{3 9 1 3 , 0 7}$ & $\mathbf{4 , 6}$ \\
\hline SNO & $\mathbf{7 1 1 9 , 0 8}$ & $\mathbf{7 4 7 9 , 8 5}$ & $\mathbf{4 , 8}$ \\
\hline
\end{tabular}

\section{Conclusions}

Tested material showed a different behavior under the four types of tests; this means that each type is suitable for a different application. The choice is done on symmetric composite only, because nonsymmetric ones are not suitable for the application of the vacuum bag technique, for the bending deformation out of the plane. The random composite has the worse mechanical characteristics for every type of effected test. The unidirectional composite is the more suitable to be for applications with predominating axial stress, as traction and bending, because the loads are parallel to the fibers direction, while the more suitable material for pure shear stress is the symmetric non orthotropic one. The vacuum bag technique can be applied in a rather simple way, because it does not ask the use of expensive sets, without complicate procedure. The diffusion of the knowledge on the design technique together with a parallel development of the production technology, working and analysis should permit reaching of greater productive volume with considerable cost reduction.

\section{REFERENCES}

[1] D. Lombardo, G. Marannano, G. Virzì Mariotti, A. Cirello - Characterisation of Fibre Glass Panels for Naval Use - ICEM12, 12th International Conference on Experimental Mechanics, 29 August - 2 September, 2004 Politecnico di Bari, Italy

[2] ASTM D3039/D3039M-93, 'Standard test method for tensile properties of polymer matrix composite materials', American Society for testing and Materials, West Conshohocken, PA, 1994

[3] UNI EN 2562, 'Prova di flessione parallela alla direzione delle fibre', Unavia, 1998.

[4] UNI EN 2563, 'Determinazione della resistenza apparente al taglio interlaminare', Unavia, 1997.

[5] ASTM D4255-83, 'Standard Guide for testing Inplane Shear Properties of composites Laminates', American Society for testing and Materials, West Conshohocken, PA, 1983.

[6] Ansys inc., User manual, Element Description, theory reference.

[7] Ever J. Barbero, "Introduction to Composite Materials Design", Taylor and Francis, Bristol, PA, 1999.

[8] Kelly A., Zweben C.: 'Comprehensive Composite Materials', Pergamon, vol. 5, (2000), 142-144.

[9] P. Compston, P. B. Jar, 'The effect of matrix toughness and loading rate on the mode II interlaminar fracture toughness of glass-fibre/polymer-ester composites', Composites science and technology, 321-333, 2001,

[10] S. R. Reid, G. Zhou, "Impact Behaviour of Fiber-Reinforced Composite Materials and Structures ", CRC, Boca Raton, USA, 2000.

[11] J. M. Whitney, Isaac M. Daniel, R. Byron Pipes, "Experimental Mechanics of Fiber Reinforced Composite Materials", Technomic Publishing Company, Lancaster, Pennsylvania, USA, 1989. 